Article

\title{
Reducing of Energy Consumption by Improving the Reclaiming Technology in Autoclave of a Rubber Wastes
}

\author{
Dan Dobrotă ${ }^{1, *(\mathbb{D})}$ and Gabriela Dobrotă ${ }^{2}$ \\ 1 Faculty of Engineering, Lucian Blaga University of Sibiu, 550024 Sibiu, Romania \\ 2 Faculty of Economics Science, Constantin Brâncuşi University of Târgu-Jiu, 210141 Targu Jiu, Romania; \\ gabi.dobrota70@gmail.com \\ * Correspondence: dan.dobrota@ulbsibiu.ro; Tel.: +40-0722-446-082
}

Received: 22 March 2019; Accepted: 15 April 2019; Published: 17 April 2019

\begin{abstract}
The devulcanization of the rubber wastes in autoclave represent a technological variant that allows the superior utilization of rubber wastes, but with high energy consumption. The researches aimed at improving the devulcanization technology in order to obtain reclaimed rubber with superior characteristics, but also with a reduction in energy consumption. An improvement to devulcanization technology consisted in vacuuming the autoclave at the end of the devulcanization process. An increase in the degree of devulcanization of the rubber from $86.83 \%$ to $93.81 \%$ and an improvement of the physico-mechanical characteristics of the reclaimed rubber was achieved by applying this technology. The realization of the new type of regenerated rubber allowed for an increase in the degree of it use for different mixtures, from 15-20 phr to 30-40 phr without substantially affecting the physical and mechanical properties of the products. Additionally, the researche has shown that, by obtaining the new type of reclaimed rubber, the duration of the refining process has been reduced by $30 \%$. All of this leads to a considerable reduction in energy consumption and transformation of the rubber waste reclaiming process into a sustainable one.
\end{abstract}

Keywords: energy consumption; reclaimed rubber; devulcanization degree; autoclave vacuum; physico-mechanical characteristics

\section{Introduction}

The recycling of secondary raw materials is an important resource-saving trend in the face of a growing decline in natural resources. Rubber wastes are sources of long-term environmental pollution due to the high resistance that they have to the action of natural factors. Upon the superior valorisation of wastes of used products that are made of rubber, two aspects have to be taken into consideration, namely environmental protection and maximization of the reuse of valuable raw materials from such wastes [1-5].

Rubber waste recycling is a major priority at present due to the large quantities of such waste that are produced worldwide. The most used solution for the recovery of rubber waste is that they are used as fuel in combustion processes, but this method is rudimentary and, in turn, polluting without offering a sustainable solution for the recovery of waste rubber [6-8]. Another commonly used method of recovering waste rubber is that the waste is transformed into granules that can be used as modifiers in different building materials, such as asphalt or concrete production $[9,10]$.

An upper variant of recycling the waste rubber is regeneration which represents a technological process of breaking the vulcanized rubber network by various methods that may be acting thermal, mechanical, chemical, or combinations thereof $[11,12]$. Most researches that were carried out in the field 
of waste rubber recycling aimed at finding an optimal technology for the reuse and devulcanization of waste rubber $[13,14]$. Through the devulcanization technological process, a high plasticity rubber product is obtained, which can be reintroduced into the manufacturing prescriptions of various rubber products. The product resulting from the regeneration process has a different composition from that of the original material due to the excipients that were introduced during the devulcanization process [15].

Before the devulcanization process, the waste rubber should be shredded, grinded, and then separated from other components that enter into their structure and should be taken into account, particularly the metal insertions [16,17]. The technological process of shredding, although it is simple in terms of kinematics, it is nevertheless very complex, because, during shredding, there is an increase in the temperature of rubber and implicitly shear resistance of it and, thus, there is an accentuated wear of tools used in shredding process, but also an increase in energy consumption (for the grinding of one kilogram of waste rubber with a particle size of $0.5 \mathrm{~mm}$, an average amount of energy is consumed: $1 \mathrm{kWh}$ [18].

Following the shredding process, devulcanization is carried out for the superior recovery of waste, which is a process by which the properties of the vulcanized polymer (the rubber) are reversed. The reclaimed rubber has a structure in the form of a gel containing a series of rather short branched chain. Thus, due to the short branched chains, if reclaimed rubber is used in the composition of a product, an increase in wear resistance of the rubber can be obtained, but also a decrease of the mechanical properties $[19,20]$.

The technological process of devulcanization is a very difficult one, because a selective rupture of sulfur bonds (S-S or C-S) must be achieved without breaking the hydrocarbon bonds. The fact that only the sulfur bonds should be ruptured, without breaking the $\mathrm{C}-\mathrm{C}$ bonds, who have about the same bonding energy determined this difficulty $[21,22]$. Optimizing the devulcanization processes only achieved a selective rupture of sulfur bonds.

The most common methods of devulcanization are those that are based on thermal or chemical-mechanical processes. Of these, the most common are the thermal processes that are carried out in technological equipment of steam-heated autoclave at a certain temperature and pressure, and, in this, in addition to the rubber granules, a series of chemical agents are added to help breaking the sulfur bonds (S-S or C-S) $[23,24]$. Additionally, an effective method of obtaining reclaimed rubber is the thermo-mechanical shear devulcanization consisting in a flow of rubber into a temperature control extruder to break the C-S and C-S $-\mathrm{S}$ bonds $[25,26]$.

Depending on the conditions in which the devulcanization process takes place, certain differences in properties are obtained for the reclaimed rubber and, thus, in the devulcanization, the type of rubber entering in the structure of the waste should be taken into account, but also by the elements that are introduced into the autoclave to ease the devulcanization process [27].

According to those presented, the technologies that are used for the devulcanization of rubber waste are a solution for the superior capitalization of this type of waste. However, all of the devulcanization technologies presented also have a number of disadvantages that are related to energy consumption, obtaining reclaimed rubber with lower characteristics and even environmental pollution. Thus, the research carried out aimed at improving the devulcanization technology in autoclaves in order to obtain a reclaimed rubber with the best degree of devulcanization and superior physico-mechanical characteristics.

In the research, a technological solution of devulcanization in the autoclave was presented that allowed: reduction of the moisture of the reclaimed rubber; increasing the degree of devulcanization of the rubber; reducing environmental pollution; reducing energy consumption; and, improving the physico-mechanical characteristics of reclaimed rubber. The proposed technological solution refers to the vacuum of the autoclave at the end of the devulcanization process that allowed for the removal of residual steam and its conversion by condensation into water waste.

In the researches products that had in composition reclaimed rubber obtained by the old and the new technology were obtained, and for each the following were analyzed: 
- the energy consumption for each of the devulcanization technologies applied;

- the degree of devulcanization of the reclaimed rubber; and,

- determination of physico-mechanical characteristics of products made using reclaimed rubber.

\section{Materials and Methods}

The recycling of rubber waste by devulcanization is quite well known, but it can still be improved in order to achieve a proper breakage of the rubber network, but also to make this technology not, environmentally polluting in itself [28]. Through the technological process of being reclaimed a plastic product (reclaimed rubber) that can be used in a certain proportion as a raw material for obtaining new rubber products is obtained.

Nowadays, waste tires and used conveyor belts account for $90 \%$ of the total resulting rubber waste $[28,29]$. Thus, it is important to find technological solutions for the treatment or disposal of these wastes. A particular problem that occurs in the recovery process of these wastes is that they are composite materials that consist of a rubber matrix and an insertion that may be metallic or textile. Under these conditions, the process of superior utilization of such wastes must be done taking into account the separation of the insertion from the rubber. As, in most cases, there are metal insertions in the structure of the tire waste and the conveyor belts, the technological process for the recovery of such wastes was taken into account in the researches. Of the two types of metallic wastes, in the researches, a conveyor belt with ST 3150 metal insert has been chosen, which is obtained by one of the largest manufacturers of conveyor belts from Romania. This type of conveyor belt, with the structure shown in Figure 1, is one of high strength and it has been used to transport coal from mining exploitations. Regarding the structure of such a waste, as in Figure 1, it is formed of two types of rubber and metal insertion. The first type of rubber is the one around the metal insertion. The composition of such a rubber, as in Table 1, according to the data provided by the conveyor belt manufacturer, is established, so as to ensure a high adhesion between the rubber and the metal insertion. With regard to the second type of rubber it has a composition, according to the data provided by the conveyor belt manufacturer, as in Table 2, which provides a high wear resistance as it enters the structure of the rolling path of the product.

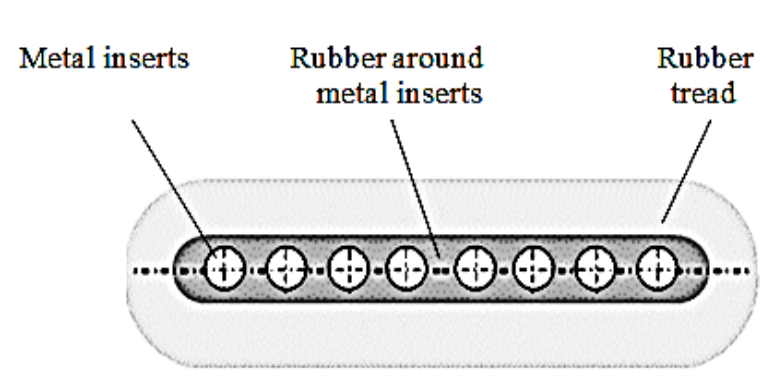

(a)

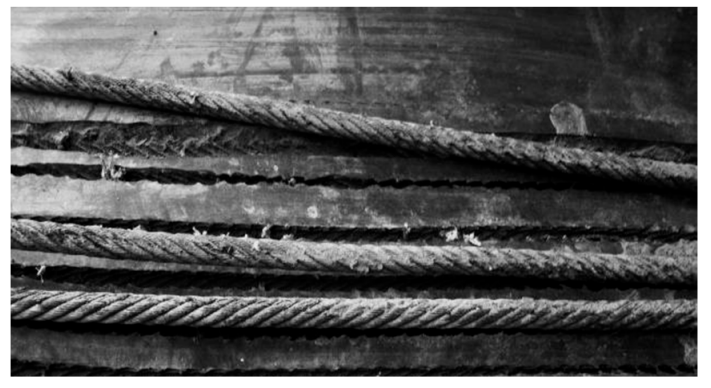

(b)

Figure 1. Structure of conveyor belt waste with metal insert. (a) waste structure; (b) image conveyor belt waste. 
Table 1. The rubber structure around the metal insertion.

\begin{tabular}{cc}
\hline Materials & phr \\
\hline Natural rubber SIR-20 & 35 \\
Styrene butadiene synthetic rubber SBR & 30 \\
Poly-butadiene synthetic rubber SKD ND & 30 \\
Reclaimed rubber & 5 \\
Naphtha & 5 \\
Carbon black HAF & 5 \\
Antioxidant 4010NA/LG(IPPD) & 1 \\
Stearin & 1 \\
Vulcanization accelerator DPG & 1 \\
Sulfur & 2 \\
Total & 115 \\
\hline
\end{tabular}

Table 2. The rubber structure from the tread.

\begin{tabular}{cc}
\hline Materials & phr \\
\hline Natural rubber SIR-20 & 15 \\
Styrene butadiene synthetic rubber SBR & 20 \\
Poly-butadiene synthetic rubber SKD ND & 25 \\
Reclaimed rubber & 40 \\
Naphtha & 5 \\
Carbon black HAF & 5 \\
Antioxidant 4010NA/LG(IPPD) & 1 \\
Stearin & 1 \\
Vulcanization accelerator DPG & 1 \\
Sulfur & 2 \\
Total & 115 \\
\hline
\end{tabular}

From the analysis of the data presented in Tables 1 and 2, it is noted that, in the rubber composition of the metal insertion area, there must be a reduced amount of reclaimed rubber but a large amount of natural rubber to achieve a high adhesion between the rubber and the metal insertion. It is also noted that, in the case of the rubber from the tread, a larger amount of reclaimed rubber and a much smaller amount of natural rubber can be used.

While taking into consideration these initial data regarding the rubber waste structure, the technological steps that allow for obtaining the reclaimed rubber by devulcanization in autoclave were considered, as shown in Figure 2. 


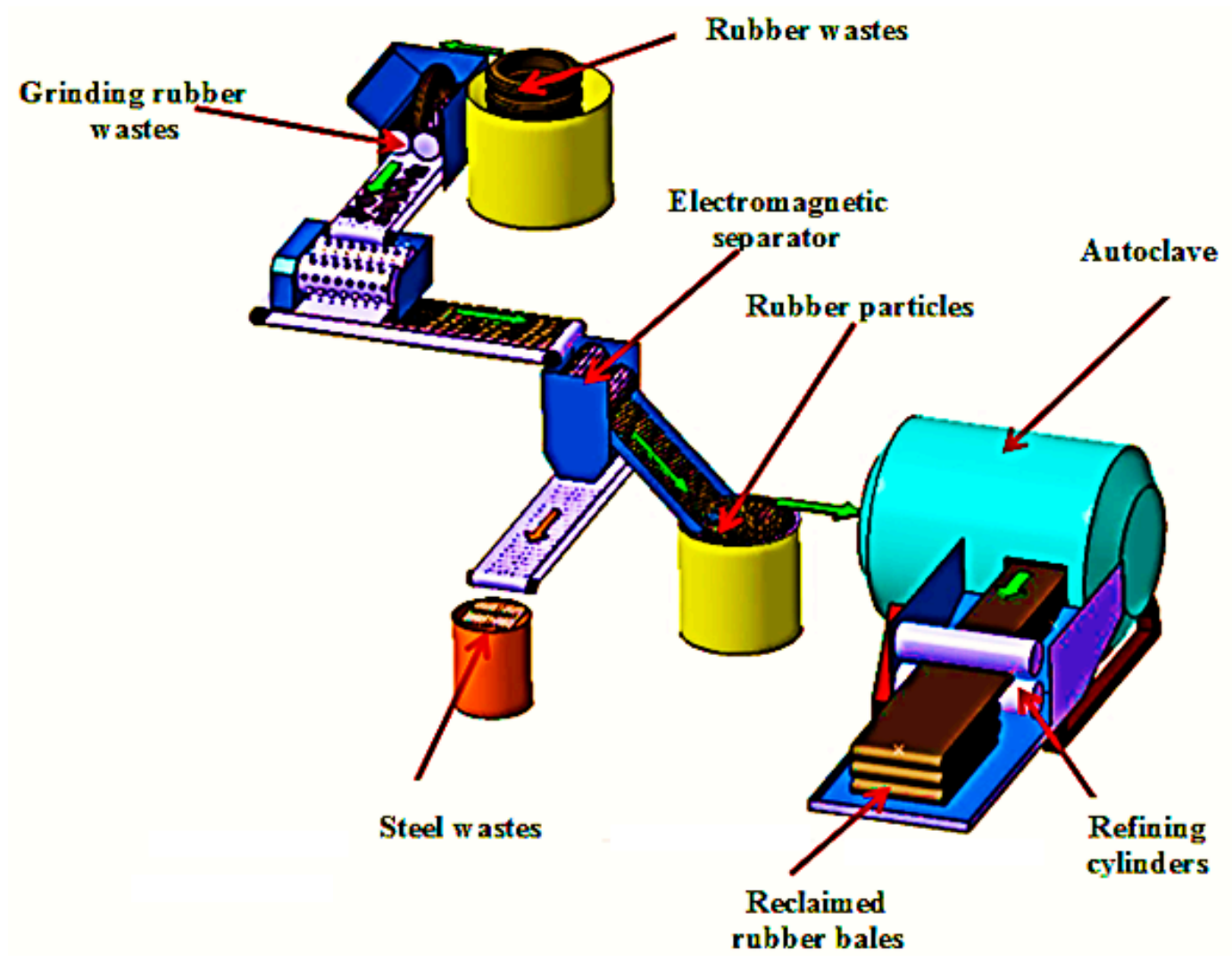

Figure 2. The structure of the technological process of obtaining reclaimed rubber by devulcanization in autoclave.

A first stage of the technological process is the grinding of waste into pieces that are as small as possible to allow the effective separation of the rubber from the metal inserts, but also a proper devulcanization. When determining the conditions in which the grinding process is to be carried out, it is necessary to consider the relation between the particle size of the grinded material, the physico-chemical and mechanical properties, the energy cost for grinding, and the parameters of the technological equipment that is used for grinding.

The grinding process is very difficult due to the very large forces that occur in the grinding process, despite its apparent simplicity, as well as the special conditions that are required for quantification of the grinding results. After the grinding operation, a separation of the rubber by the metal insert was performed, with an electromagnetic separator. The separation resulted in two distinct components, namely the metal insert and the rubber, without the presence of other components, such as textile inserts.

Rubber wastes were initially shredded on a shredder machine, and afterwards they were grinded using a disc mill to obtain granules of size between 0.5 and $3 \mathrm{~mm}$. These granules were devulcanized, while taking into account two variants of devulcanization, and after this step, samples by revulcanization were refined and resalable while taking into account the reclaimed rubber that was obtained by the two methods of devulcanization. Classically, the technological process of devulcanization in the autoclave is accomplished under certain conditions of temperature and pressure in the autoclave, but also by adding substances to aid the devulcanization process.

In the researches, in the first stage, an industrial autoclave was used, which was loaded with $900 \mathrm{~kg}$ of rubber particles, $7 \mathrm{~kg}$ Di-xylene Di-Sulphide (reclaiming agent produced by Arihant oil and Chemicals), and $70 \mathrm{~kg}$ of mineral oil (plasticizer). After loading, the autoclave was closed and steam was introduced into it until a working pressure (28-30 bar) was reached. After this step, the steam inlet valves have been closed in the autoclave and the heating resistors were connected, which allowed for a pressure increase of up to $40 \mathrm{bar}$ and a temperature of $225^{\circ} \mathrm{C}$. Thus, the autoclave mixture was maintained under these conditions for $2.5 \mathrm{~h}$. After the devulcanization process was completed, 
a controlled depressurization of the autoclave was carried out until the temperature had fallen to 90-100 ${ }^{\circ} \mathrm{C}$ and the pressure gauges indicated zero. Additionally, at the end of the devulcanization cycle, the autoclave was cooled, which consisted in the decoupling of the resistances and the opening of the steam exhaust valves.

In the second stage of the research, the same conditions for devulcanization were used as in the first stage, only that, after the devulcanization process was completed and the autoclave pressure dropped to 1.2-1.3 bar, it was coupled to a vacuum system by which the entire amount of steam in the autoclave was removed, as in Figure 3. The vacuum system that was used has allowed autoclave pressure to be lowered to $0.1-0.2$ bar, and this contributes to an improvement in the devulcanization conditions of the rubber. By creating this low pressure, the steam that was taken from the autoclave was transferred to a container (Figure 3), where, after condensation, they were transformed into residual water. The residual water that was obtained through the vacuuming process was introduced into a wastewater treatment plant. Thus, the application of this method avoids the pollution of the environment due to the fact that this waste water is no longer evacuated in the environment in the form of vapors, as is the case with classical technology.

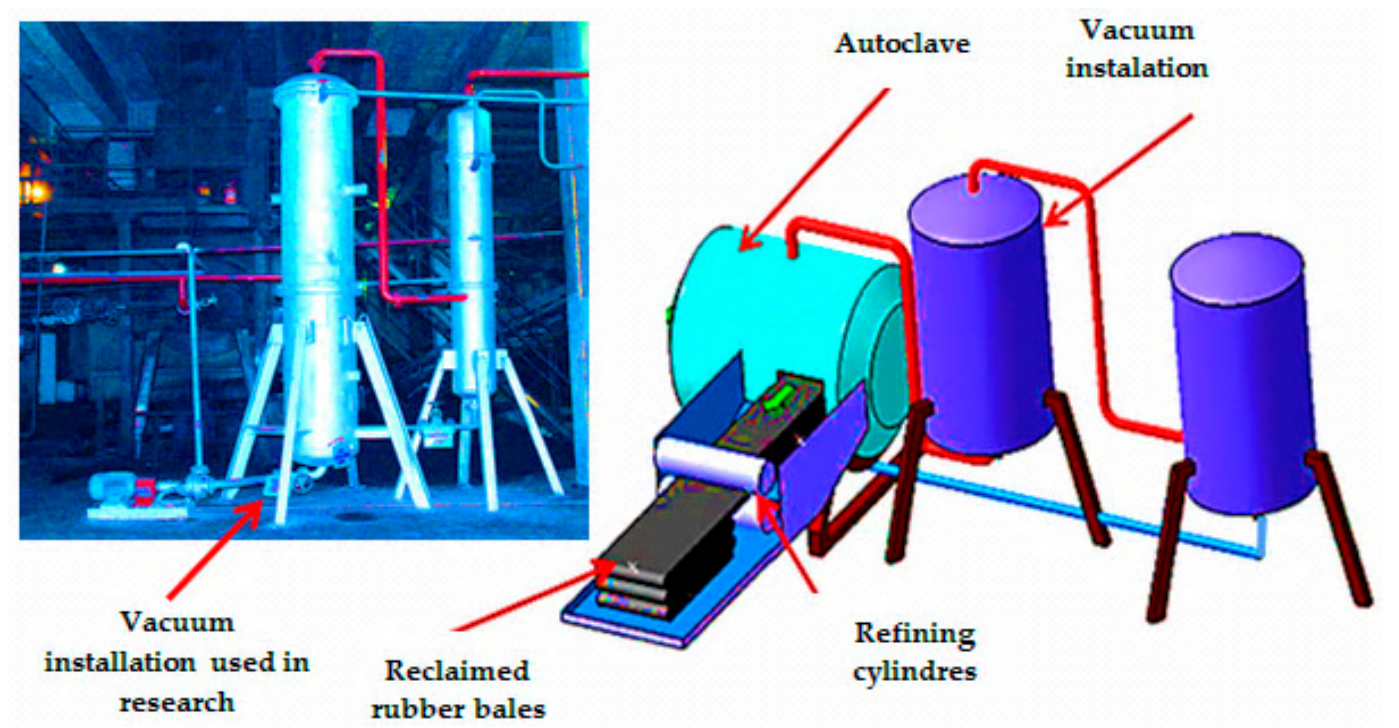

Figure 3. Vacuum system for autoclave.

Thus, by adopting this technical solution, an attempt was made to remove a large part of the water waste vapor from the autoclave in order to obtain a considerable decrease of moisture of reclaimed rubber. Additionally, by vacuuming the autoclave, better adhesion conditions between the rubber particles are created, given that there is no more moisture on their surface.

After the rubber devulcanization stage, they were refined on a refining line consisting of five refineries and one strainer. The refining of the devulcanized rubber (through mechanical action) consists in passing among the cylinders of five refiners and a strainer, in order to achieve a additional homogenization of the material, plasticizing, refining, and making the bales of rubber reclaimed. The first refiner has the role of homogenization of the material, refineries 2 and 3 perform primary refining, refiner 4 performs the secondary refinery, and refinery 5 is used for fine refining and the production of reclaimed rubber bales. The refineries were mounted in line with the conveyor belts between them. The distance between the cylinders decreases from refiner 1 to refiner 5 , so that the pulverulent material in the autoclave is bonded to sheets of varying thickness. The strainer was mounted etween refiner 3 and 4 to filter the material in order to retain the possible impurities. As for the distance between the refinery cylinders, they had the following values: refiner 1: $0.8 \mathrm{~mm}$; refiner 2: $0.5 \mathrm{~mm}$; refiner 3: $0.4 \mathrm{~mm}$; refiner 4: $0.3 \mathrm{~mm}$; and, refiner 5: $0.15 \mathrm{~mm}$. A series of technical equipments and specific standards has been considered in order to determine the physical and mechanical properties of 
reclaimed rubber. Thus, Table 3 presents the equipments and specific standards used to establish each physico- mechanical characteristic.

Table 3. Specific equipments and standards used to determine the physical and mechanical characteristics.

\begin{tabular}{|c|c|c|}
\hline $\begin{array}{c}\text { Physical and Mechanical } \\
\text { Characteristic }\end{array}$ & Equipment & Standard \\
\hline$\%$ vulcanization & Rheometer Model: (ODR 2000) & ASTM D 1646 \\
\hline $300 \%$ modulus, $\mathrm{MPa}$ & $\begin{array}{c}\text { Machine of Traction Lloyd } \\
\text { instruments a trademark of AMETEK } \\
\text { tip LR10K PLUS 01/3052 }\end{array}$ & ISO 4662/2009 \\
\hline Hardness, ${ }^{\circ} \mathrm{Sh}$ & Durometer BAREISS HPE tip Shore A & SR ISO 27619-1/2011 \\
\hline Viscosity Mooney ML $(1+4) 100{ }^{\circ} \mathrm{Cb}$ & $\begin{array}{c}\text { Viscometer Mooney Model: TO-230 } \\
\text { Machine of Traction Lloyd }\end{array}$ & ASTM D1646 \\
\hline Tensile strength, $\mathrm{MPa}$ & $\begin{array}{l}\text { instruments a trademark of AMETEK } \\
\text { tip LR10K PLUS 01/3052 }\end{array}$ & SR ISO 37:2010 \\
\hline Residual elongation, $\%$ & $\begin{array}{c}\text { Machine of Traction Lloyd } \\
\text { instruments a trademark of AMETEK } \\
\text { tip LR10K PLUS 01/3052 }\end{array}$ & SR ISO 37:2010 \\
\hline Elongation at break, \% & $\begin{array}{c}\text { Machine of Traction Lloyd } \\
\text { instruments a trademark of AMETEK } \\
\text { tip LR10K PLUS 01/3052 }\end{array}$ & SR ISO 37:2010 \\
\hline Abrasion resistance, $\mathrm{mm}^{3}$ & Abrazimeter Model C5000 & ISO 11998 \\
\hline Density, $\mathrm{g} / \mathrm{cm}^{3}$ & Balance SARTORIUS 2462 & SR ISO $2781+C 1 / 2001$ \\
\hline
\end{tabular}

\section{Results and discussions}

The experimental researches aimed to determine the effects of the autoclave vacuuming process on the reclaimed rubber characteristics, as well as on the energy that is consumed in the two technological process variants.

In the researches made, two types of reclaimed rubber were obtained, namely:

- RR1-reclaimed rubber obtained by devulcanization in the autoclave; and,

- RR2 - reclaimed rubber obtained by devulcanization in the autoclave with its vacuum.

After the completion of the devulcanization process and achieving the depressurization of the autoclave, the water vapors were removed from this and the condensation of the removed vapors resulted in a volume of approximately $900 \mathrm{~L}$ of residual water. Since the depressurization of the autoclave does not eliminate the entire amount of water vapor, it has been connected to a vacuum plant to be able to discharge the entire amount of water vapor that was left in the autoclave, as in Figure 3. By removing the water vapor from the autoclave by means of the vacuum instalation, it has improved the devulcanization process in the autoclave, with effects on the properties of the devulcanized rubber obtained.

Thus, it has been found that through the vacuuming of the autoclave vapors were removed, and they were converted to residual water by cooling. The amount of water waste obtained in the experimental research varied between 86-90 L for a $900 \mathrm{~kg}$ load of reclaimed rubber. Thus, through the vacuuming process of the autoclave, a reduction in the humidity of the devulcanized rubber was achieved. Additionally, the moisture difference of the devulcanized rubber samples could be visually observed, as in Figure 4. Reducing the moisture of the devulcanized rubber has created the conditions for an increase in the degree of devulcanization of rubber wastes. At the same time, the rubber particles adhere to each other after the devulcanization process, with a better adherence being observed when applying the improved devulcanization technology. 


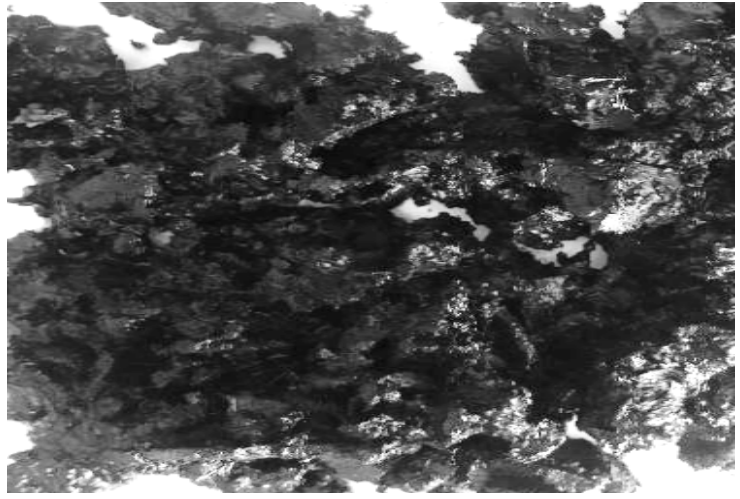

(a)

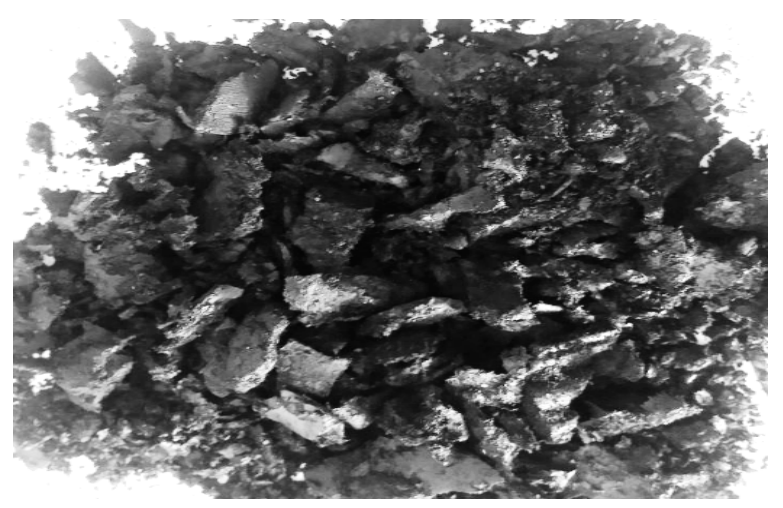

(b)

Figure 4. Devulcanized rubber samples in autoclaves. (a) devulcanized rubber sample in the autoclave by classic technology; and, (b) devulcanized rubber sample in autoclave with vacuuming the autoclave.

As a result of the devulcanization process, the reclaimed rubber was introduced for refining on a refinery line and, thus, from this stage, a difference was found between the properties of the reclaimed rubber that was obtained by the two technological processes. The one thing found in this phase of obtaining the reclaimed rubber was that, during refining and around refining installations, there was a large amount of water vapor in RR1 reclaimed rubber and, in the case of RR2 reclaimed rubber, there was no water vapor. The presence of water vapor during the refining process can cause a reduction in the properties of the reclaimed rubber, but at the same time, there is an intense pollution of the working environment. Due to the moisture and inadequate devulcanization in RR1 reclaimed rubber, it was observed that there is no adherence between the reclaimed rubber sheets after the refining, whereas, in the case of the reclaimed rubber RR2, there is good adhesion between the reclaimed rubber sheets, as in Figure 5. This can be explained by the fact that, in the case of RR1, there is no proper drainage and good adherence between the rubber sheets, whereas, in case of the RR2 rubber, it is obtained a high devulcanization and a good adhesion between the rubber sheets.

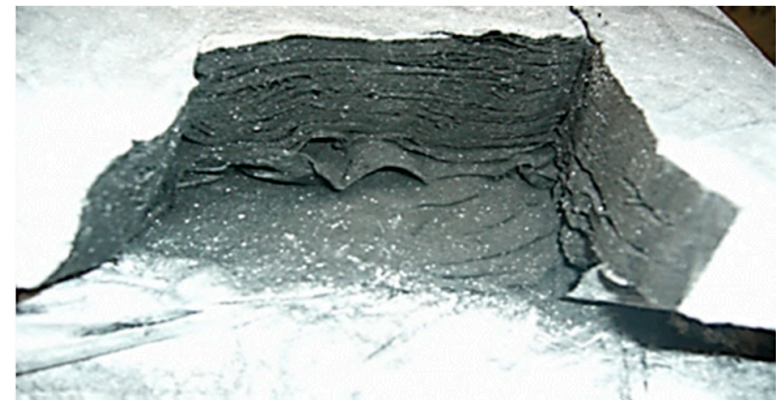

(a)

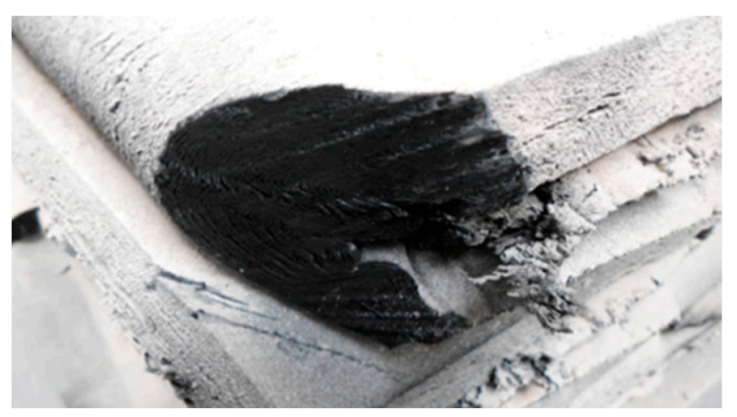

(b)

Figure 5. Reclaimed rubber samples. (a) the reclaimed rubber sample (RR1) obtained through the classic technology; (b) reclaimed rubber sample (RR2) obtained through improved technology.

Additionally, by reducing the humidity of the devulcanized rubber, an improvement in the properties of the reclaimed rubber and, implicitly, of the physico-mechanical characteristics of the products that were made with the use of reclaimed rubber can be obtained.

Under these conditions, the researches aimed at establishing the degree of devulcanization that was obtained for the two types of reclaimed rubber, of the properties of the products in which the two types of specimens are included, in which RR1 and RR2 regenerated rubber were incorporated, but also the energy consumptions that are involved in the use of the two devulcanization technologies. 


\subsection{Determining the Degree of Devulcanization of Reclaimed Rubber}

The degree of devulcanization of the rubber was determined for the two types of reclaimed rubber RR1 and RR2. The samples for determining the degree of devulcanization were taken after the refining operation of the two types of reclaimed rubber, and each sample had a mass of $0.5 \mathrm{~kg}$. To determine the properties of reclaimed rubber, six samples from different batch were taken for each type of reclaimed rubber (RR1, RR2). The rubber properties were established as an average of the degree of devulcanization of the 6-RR1 reclaimed rubber samples and the 6-RR2 reclaimed rubber samples.

Thus, for the determination of the degree of devulcanization, the test method of ASTM D6814-02 standard was used. In the first step for the devulcanized rubber samples, the percentage of acetone extract was determined while taking into account the ASTM-D297 standard. The results obtained showed that the two types of rubber had a proportion of approximately acetone extract RR $1=21 \%$ and $\mathrm{RR} 2=19 \%$, and these values are within the maximum admissible $30 \%$. After this step, the reclaimed rubber samples were dried in a ventilated oven for $16 \mathrm{~h}$ at a temperature of $70{ }^{\circ} \mathrm{C}$.

The samples had a thickness of $2 \mathrm{~mm}$ and weighed initially, with the initial weight being determined $\left(m_{i}\right)$. They were introduced into toluene for a period of $72 \mathrm{~h}$ to determine the mass of swollen samples $\left(m_{g}\right)$. Additionally, in order to maintain the properties of toluene, it has been replaced 24 to $24 \mathrm{~h}$. After swelling of the rubber in the toluene bath, the samples were wiped off the water and then weighed to determine the mass of the swollen samples $\left(m_{g}\right)$. After this step, the samples were dried in an oven at a temperature of $68^{\circ} \mathrm{C}$ for $18 \mathrm{~h}$ and cooled to room temperature and their final mass was determined $\left(m_{f}\right)$. The densities of the samples taken were measured according to ISO 2781/2008 and the value was determined as an average of values for three distinct specimens. Additionally, the mass of samples was set in the air $\left(m_{\text {air }}\right)$ and weighed again as they were immersed in methanol. After the unfolding of these steps the density of the samples was determined while using the equation:

$$
\rho_{r}=\rho_{\text {ethanol }} \cdot \frac{m_{\text {air }}}{m_{\text {air }}-m_{\text {methanol }}}
$$

where $\rho_{r}$ is the densities of the samples; $\rho_{\text {ethanol }}$-density of ethanol; $m_{\text {air }}$-sample mass in the air; $m_{\text {methanol }}$-methanol mass.

The calculations for the average density determination of the rubber samples were made using equation 1 and the following average densities for the rubber specimens were obtained: $\rho_{R R 1}=1.39 \mathrm{~g} / \mathrm{cm}^{3}$ for the RR1 reclaimed rubber and $\rho_{R R 2}=1.28 \mathrm{~g} / \mathrm{cm}^{3}$ for the RR2 reclaimed rubber, with this difference being explained through the different conditions in which devulcanization was made.

To determine the degree of devulcanization of the two types of rubber, it was necessary to establish their crosslinking density, which was compared with the crosslinking density of the initial rubber. The crosslinking density is the number of moles of the crosslinked base units relative to the unit weight of the crosslinked polymer (rubber). The reticular density crosslinking density for the two samples was determined as a result of measurements on the toluene swollen samples at $25^{\circ} \mathrm{C}$. Furthermore, the modified Flory-Rehner equation for transfunctional networks was used for the reticular crosslinking density determination.

$$
v=-\frac{\ln \left(1-v_{c g}\right)+v_{c g}+v_{c g}^{2} \cdot \chi_{c t}}{v_{t}\left(v_{c g}^{\frac{1}{3}}-\frac{2}{\phi} v_{c g}\right)}
$$

where $v_{t}=106.3 \mathrm{~cm}^{3} / \mathrm{mol}$ is the molar volume of toluene; $v_{c g}$-is the volume of the rubber fraction in the inflated sample, $\phi=4$ is the functionality of the reticulation; and, $\chi_{c t}=0.391$ is the interaction parameter between rubber and toluene.

In the researches, the fraction of toluene absorbed by each samples was determined, and this gave us a series of informations on the degree of devulcanization of the rubber. Under these conditions, 
the volume fraction of the rubber in the swollen samples $v_{c g}$ was determined starting from the swelling degree $G$, using the equations:

$$
\begin{gathered}
v_{c g}=\frac{1}{1+G} \\
G=\frac{\left(m_{g}-m_{f}\right)}{m f} \cdot \frac{\rho_{c}}{\rho_{t}}
\end{gathered}
$$

where $\rho_{c}$-the density of the rubber, $\rho_{t}=0.8714 \mathrm{~g} / \mathrm{cm}^{3}$ — the density of the toluene.

When considering the previous equations, the swelling characteristics and crosslinking densities of the two types of reclaimed rubber (RR1, RR2) have been established, as in Table 4.

Table 4. Swelling characteristics and crosslinking density of the samples.

\begin{tabular}{cccccccc}
\hline Sample Symbol & $m_{i}, \mathbf{k g}$ & $m_{g}, \mathbf{k g}$ & $m_{f}, \mathbf{k g}$ & Rubber Density, $\mathbf{g} / \mathbf{c m}^{\mathbf{3}}$ & $G$ & $v_{c g}$ & $V_{f}\left(\mathbf{1 0} \mathbf{0}^{-\mathbf{5}} \mathbf{~ m o l} / \mathbf{c m}^{3}\right)$ \\
\hline RR1 & 0.516 & 0.934 & 0.491 & 1.39 & 1.44 & 0.409 & 4.28 \\
RR2 & 0.487 & 0.922 & 0.481 & 1.28 & 1.34 & 0.427 & 2.01 \\
\hline
\end{tabular}

The devulcanized samples had different crosslinking densities, so that the samples that wee made of devulcanized rubber RR1 had a crosslinking density $V_{f 1}=4.28 \times 10^{-5} \mathrm{~mol} / \mathrm{cm}^{3}$, and the samples that were made of devulcanized rubber RR2 had a crosslinking density $V_{f 2}=2.01 \times 10^{-5} \mathrm{~mol} / \mathrm{cm}^{3}$, while the initially vulcanized rubber had a crosslinking density $V_{i}=32.5 \times 10^{-5} \mathrm{~mol} / \mathrm{cm}^{3}$.

In the final stage, the degrees of devulcanization of the two types of rubber were calculated. In this respect, Equation (4) was used:

$$
\% \text { devulc }=\left[1-\frac{V_{f}}{V_{i}}\right] \cdot 100
$$

where $V_{\mathrm{i}}$ and $V_{f}$ are the crosslinking densities of the rubber before and after devulcanization.

Following the application of Equation (4), different degrees of devulcanization were obtained for the two types of rubber. Thus, for the samples made of reclaimed rubber RR1, an average degree of devulcanization of $86.83 \%$ was obtained, and for the samples that were made of reclaimed rubber RR2, an average degree of devulcanization of $93.81 \%$ was obtained. These high degrees of devulcanization can also be explained by the fact that only the grinded rubber particles have been introduced into the autoclave without the presence of other inclusions, such as textile inserts.

These large differences between the degrees of devulcanization that were obtained for the two types of rubber are explained by the fact that, in RR1, the presence of moisture causes the energy consumed in the refining process to be used to eliminate moisture and much less to homogenise and breaking the links of rubber. In the case of RR2, the low moisture content causes that the breaking process of links of rubber to continue in the refining process and to improve the degree of devulcanization.

It is necessary to carry out the refining process for a longer time and even resume the refining cycle for refineries 4 and 5 of the refining line in order to obtain a higher degree of devulcanization for RR1. This means very high energy consumption, but also a sharp pollution of the working environment. Vacuuming the autoclave involves low energy consumption, but also an increase in the degree of devulcanization of rubber with effects on the characteristics of rubber products that are made with the use of reclaimed rubber.

\subsection{Determination of Physical and Mechanical Characteristics of Products Made with the Use of Reclaimed Rubber}

Two types of samples were prepared to determine the characteristics of products that are made with the use of reclaimed rubber: 
- samples made with the use of devulcanized rubber through the classic procedure RR1; and,

- samples made using devulcanized rubber obtained by devulcanization with autoclave vacuuming, RR2.

Additionally, the two types of reclaimed rubber that have been used to obtain samples that had at base a mixture of rubber that also came into the structure of rubber waste that was subjected to the regeneration process. Thus, Table 5 shows the composition of the rubber mixture used to make the samples using the two types of regenerated rubber.

Table 5. Composition of the rubber mixture made of the two types of regenerated rubber, phr.

\begin{tabular}{|c|c|c|c|c|c|c|c|c|c|c|c|c|}
\hline \multirow[t]{2}{*}{ Materials } & \multicolumn{5}{|c|}{$\begin{array}{l}\text { Samples Made with the Use of } \\
\text { Regenerated Rubber RR1 }\end{array}$} & \multicolumn{7}{|c|}{$\begin{array}{l}\text { Samples Made with the Use of Regenerated Rubber } \\
\text { RR2 }\end{array}$} \\
\hline & RR10 & RR11 & RR12 & RR13 & RR14 & RR15 & RR20 & RR21 & RR22 & RR23 & RR24 & RR25 \\
\hline Styrene butadiene synthetic rubber SBR & 35 & 30 & 25 & 25 & 25 & 25 & 35 & 30 & 25 & 25 & 25 & 25 \\
\hline Poly-butadiene synthetic rubber SKD ND & 35 & 30 & 25 & 25 & 25 & 25 & 35 & 30 & 25 & 25 & 25 & 25 \\
\hline Reclaimed rubber & 0 & 10 & 20 & 30 & 40 & 50 & 0 & 10 & 20 & 30 & 40 & 50 \\
\hline Naphtha & 5 & 5 & 5 & 5 & 5 & 5 & 5 & 5 & 5 & 5 & 5 & 5 \\
\hline Stearin & 1 & 1 & 1 & 1 & 1 & 1 & 1 & 1 & 1 & 1 & 1 & 1 \\
\hline Vulcanization accelerator DPG & 1 & 1 & 1 & 1 & 1 & 1 & 1 & 1 & 1 & 1 & 1 & 1 \\
\hline Sulfur & 2 & 2 & 2 & 2 & 2 & 2 & 2 & 2 & 2 & 2 & 2 & 2 \\
\hline Total & 115 & 115 & 115 & 115 & 115 & 115 & 115 & 115 & 115 & 115 & 115 & 115 \\
\hline
\end{tabular}

The samples were made using the two types of regenerated rubber with different incorporation rates of regenerated rubber, as in Table 5, so that their incorporation rate in the mixture was between 0 phr and $50 \mathrm{phr}$ (6 test specimens for each type of regenerated rubber used).

Moreover, the samples were also vulcanized in a $250 \times 250 \mathrm{~mm}$ mold with a thickness of $2 \mathrm{~mm}$ at a vulcanization temperature of $155^{\circ} \mathrm{C}$, with a pressure of 145 bar. The choice of these parameters for the vulcanization operation was made while taking into account the technological parameters that were used to obtain the ST 3150 conveyor belts.

A Monsanto oscillating disk rheometer (ODR 2000) operating at a frequency of $1.66 \mathrm{~Hz}$ was used for determining the optimum curing time (t90). The rheometer used is ARES product Rheometric Scientific, Piscataway, NJ, SUA. To carry out the measurements, the samples were punched as circular discs of $25 \mathrm{~mm}$ in diameter and $2 \mathrm{~mm}$ thick and then mounted in the empty space between the plates of the rheometer. Table 6 shows the values that were set for the optimum curing time (t90) of the samples.

Table 6. Optimum curing time ( $(90)$ of the mixes as evaluated by a Monsanto Rheometer.

\begin{tabular}{|c|c|c|c|c|c|c|c|c|c|c|c|c|}
\hline \multirow{2}{*}{$\begin{array}{c}\text { t90 from } \\
\text { Monsanto } \\
\text { Rheometer }\end{array}$} & \multicolumn{6}{|c|}{$\begin{array}{c}\text { Samples Made with the Use of Regenerated } \\
\text { Rubber RR1 }\end{array}$} & \multicolumn{6}{|c|}{$\begin{array}{l}\text { Samples Made with the Use of Regenerated } \\
\text { Rubber RR2 }\end{array}$} \\
\hline & RR10 & RR11 & RR12 & RR13 & RR14 & RR15 & RR20 & RR21 & RR22 & RR23 & RR24 & RR25 \\
\hline $\begin{array}{l}\text { Optimum } \\
\text { curing time } \\
\text { (t90) (min) }\end{array}$ & 6.1 & 5.9 & 5.8 & 5.7 & 5.4 & 5.1 & 6.1 & 5.7 & 5.4 & 5.1 & 4.7 & 4.1 \\
\hline
\end{tabular}

The rubber from the 12 samples made was subjected at various physico-mechanical attempts, while using the specific equipment and standards shown in Table 3, and the results that are presented in Table 7 were obtained. For each of these, samples specific to the type of test (for example, dumbbell type for determining the tensile strength) was made. 
Table 7. The physical and mechanical characteristics of the rubber in the samples made using the two types of reclaimed rubber.

\begin{tabular}{|c|c|c|c|c|c|c|c|c|c|c|c|c|}
\hline \multirow{2}{*}{$\begin{array}{l}\text { Physical and } \\
\text { Mechanical } \\
\text { Characteristic }\end{array}$} & \multicolumn{6}{|c|}{$\begin{array}{l}\text { Samples Made with the Use of Regenerated } \\
\text { rubber RR1 }\end{array}$} & \multicolumn{6}{|c|}{$\begin{array}{l}\text { Samples Made with the Use of Regenerated } \\
\text { Rubber RR2 }\end{array}$} \\
\hline & RR10 & RR11 & RR12 & RR13 & RR14 & RR15 & RR20 & RR21 & RR22 & RR23 & RR24 & RR25 \\
\hline $\begin{array}{l}\text { Tensile strength, } \\
\mathrm{MPa}\end{array}$ & 9.3 & 8.9 & 8.1 & 7.4 & 6.3 & 5.4 & 9.3 & 9.1 & 8.9 & 8.7 & 7.3 & 6.1 \\
\hline Hardness, ${ }^{\circ}$ Sh A & 62 & 63 & 66 & 70 & 75 & 84 & 62 & 63 & 64 & 66 & 72 & 76 \\
\hline $\begin{array}{l}300 \% \text { modulus, } \\
\mathrm{MPa}\end{array}$ & 6.7 & 6.3 & 5.2 & 5.1 & 4.4 & 3.7 & 7.7 & 7.5 & 7.2 & 7.0 & 6.5 & 5.9 \\
\hline $\begin{array}{l}\text { Residual } \\
\text { elongation, \% }\end{array}$ & 13 & 14 & 15 & 18 & 21 & 23 & 13 & 14 & 14,5 & 15 & 17 & 20 \\
\hline $\begin{array}{l}\text { Elongation at } \\
\text { break, \% }\end{array}$ & 581 & 575 & 561 & 532 & 511 & 493 & 581 & 563 & 548 & 533 & 515 & 498 \\
\hline $\begin{array}{l}\text { Abrasion } \\
\text { resistance, } \mathrm{mm}^{3}\end{array}$ & 1.11 & 1.13 & 1.23 & 1.30 & 1.37 & 1.44 & 1.11 & 1.12 & 1.13 & 1.14 & 1.21 & 1.33 \\
\hline $\begin{array}{l}\text { \% rubber } \\
\text { vulcanization }\end{array}$ & 96.15 & 96.65 & 97.13 & 98.07 & 98.01 & 99.09 & 96.15 & 96.34 & 96.85 & 97.6 & 97.91 & 98.21 \\
\hline $\begin{array}{l}\text { Viscosity Mooney } \\
\text { ML }(1+4) 100^{\circ} \mathrm{Cb}\end{array}$ & 71 & 75 & 81 & 89 & 95 & 101 & 71 & 73 & 74 & 75 & 83 & 91 \\
\hline Density, $\mathrm{g} / \mathrm{cm}^{3}$ & 1.25 & 1.27 & 1.33 & 1.40 & 1.48 & 1.45 & 1.25 & 1.26 & 1.27 & 1.28 & 1.31 & 1.35 \\
\hline
\end{tabular}

In order to observe the influence of the use of the two types of reclaimed rubber on the physico-mechanical characteristics of the samples, a graphical analysis of the dependence of these characteristics was made on the rate of incorporation of the two types of reclaimed rubber in the mixture that was used to make the samples (Figure 6, Figure 7).

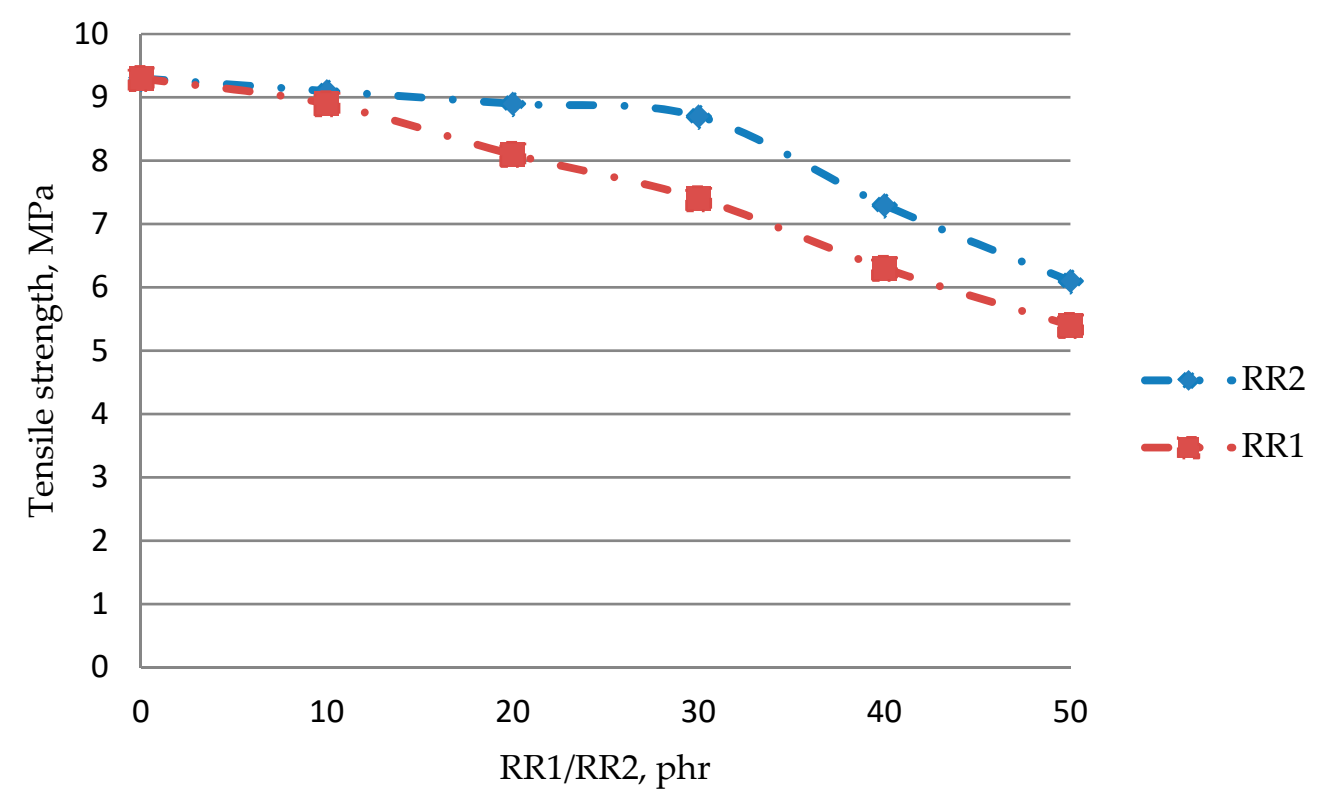

Figure 6. Evolution of tensile strength according to the percentage of reclaimed rubber used to make the samples. 


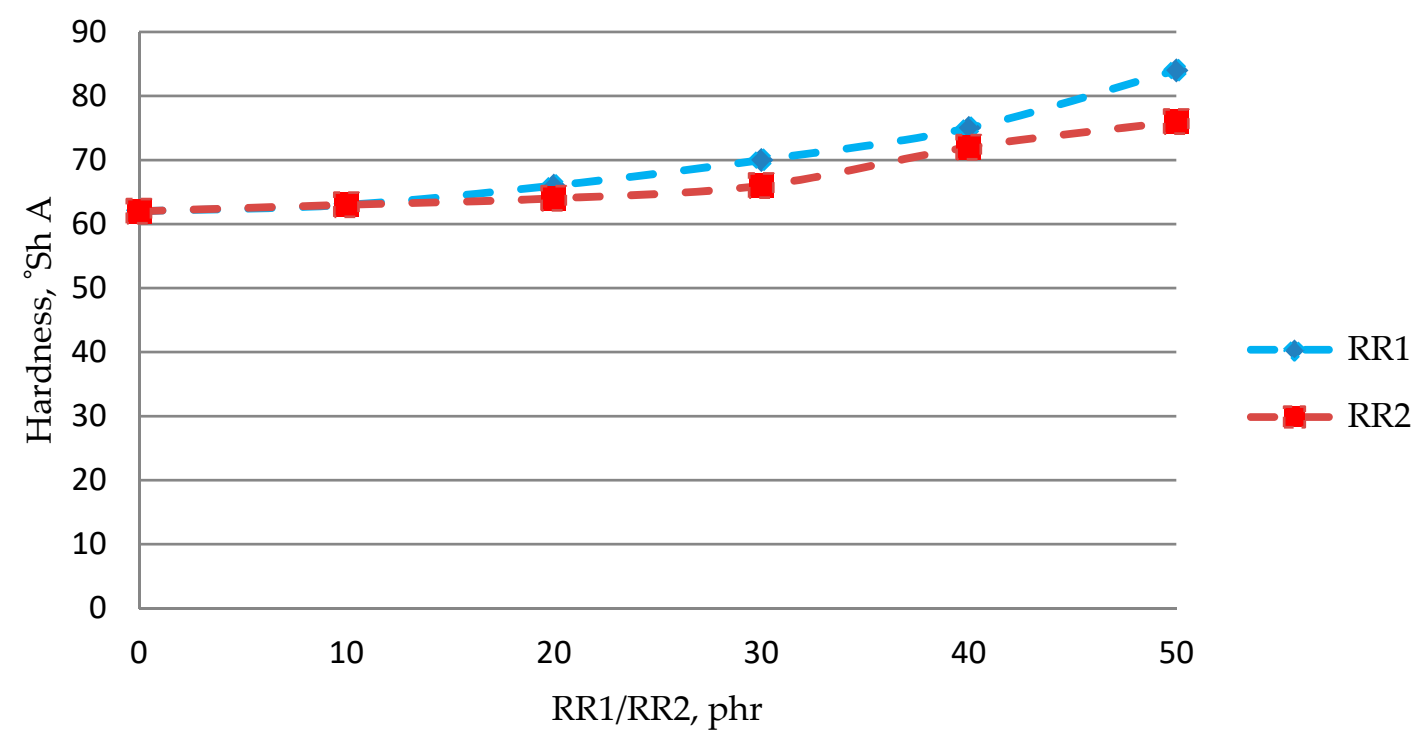

Figure 7. Evolution of hardness according to the percentage of reclaimed rubber used to make the samples.

Following the analysis of the physical and mechanical characteristics of the rubber in the samples that were made using the two types of regenerated rubber, the following were established:

- the physico-mechanical properties of rubber mixtures containing reclaimed rubber are maintained at values that are close to the situation where only new materials are used if the percentage of regenerated rubber used does not exceed 15-20 phr in the case of RR1 and 35-40 phr, respectively, to RR2;

- the degree of vulcanization of the rubber in the samples made using RR1 reclaimed rubber is much higher than of the samples made using RR2 reclaimed rubber, and this can be explained by the fact that, in the case of samples made of RR1 reclaimed rubber, the process of making the samples started from a higher initial degree of vulcanization (13.67\%) and, in the case of samples made using RR2 reclaimed rubber from a lower degree of vulcanization (6.19\%);

- also, it has been found that the use of a reclaimed rubber in the composition of the mixture in a proportion of about $40 \mathrm{phr}$ determine a uniformity of the degree of vulcanization, regardless of the type of regenerated rubber used;

- the elastic properties are different for the samples made using the two types of reclaimed rubber, in the sense that the samples that were made of RR2 reclaimed rubber have a higher elasticity, which shows that such reclaimed rubber can be used in good conditions for the manufacture of products that require a good elasticity, being possible to replace a certain amount of natural rubber;

- the hardness of the rubber is lower in the sample that was made using RR2 reclaimed rubber, and this demonstrates that the new devulcanization technology in the autoclave with its vacuum allows to obtain a reclaimed rubber that can be used in a high percentage in the composition of some products of which a high elasticity is required, which until the application of this technology was not possible;

- the viscosity of the samples that was achieved with the use of RR2 rubber is higher than that achieved with the use of RR1 reclaimed rubber. This is explained by the fact that, by applying the classic devulcanization process in autoclave, a higher moisture remains in reclaimed rubber and its devulcanization degree is a low one;

- the mechanical characteristics that were established for the samples made with the use of the two types of reclaimed rubber show that they are superior to the obtained samples using reclaimed rubber RR2, and this allows for the use of this type of reclaimed rubber in a high proportion in the 
composition of the different mixtures of rubber used in the manufacturing of rubber products requiring high technical performance, such as tires and conveyor belts; and,

- abrasion resistance is clearly superior to the samples that have, in their structure, RR2 reclaimed rubber, which demonstrates that this type of rubber can be used in optimal conditions and for makito achieve the rolling surfaces of some products that are highly demanded to abrasive wear, such as tires and conveyor belts.

\subsection{The analysis of the Process of Obtaining Reclaimed Rubber in Terms of Energy Consumption}

The process of capitalizing rubber waste by devulcanization in autoclaves can become sustainable to the extent that it ensures low energy consumption and, in turn, is a non-polluting process.

The change proposed to the devulcanization technology aimed, besides improving the characteristics of the reclaimed rubber, a reduction of the energy consumption and of the noxes that were emitted during the devulcanization process.

After the operation of devulcanization of the rubber in the autoclave, its refining operation follows. This operation is one that involves a considerably high energy consumption of about $2.5 \mathrm{kWh} / \mathrm{kg}$.

This energy consumption value is valid if a reclaimed rubber RR1 is obtained. When reclaimed rubber was made by improved devulcanization technology (RR2), the refining time was reduced by about $40 \%$, and thus the energy consumption in this operation has reached about $1.5 \mathrm{kWh} / \mathrm{kg}$.

The technological process of manufacturing of rubber products through vulcanization is a great energy consumer. Thus, optimizing the vulcanization process of rubber products can lead to reducing the energetic consumptions. An important parameter of the vulcanization process is optimum curing time (t90). From the data presented in Table 6, the optimum curing time ( 190$)$ values are different for the samples that were made from the two types of reclaimed rubber. Thus, if the optimum curing time ( 190$)$ is analyzed, as in Table 6, it was observed that, for the specimens made using 20 phr RR1, reclaimed rubber $\mathrm{t} 90=5.8 \mathrm{~min}$, and for the specimens made using $40 \mathrm{phr}$ regenerated rubber $\mathrm{RR} 2, \mathrm{t} 90=4.7 \mathrm{~min}$. The maximum incorporation degree of $20 \mathrm{phr}$ for RR1 namely $40 \mathrm{phr}$ for RR 2 were considered, because, over these values, the rubber blends made have inadequate properties. The difference of optimal curing time ( $\mathrm{t} 90$ ) of about $19 \%$ in favor of the RR2 reclaimed rubber mixture demonstrates that energetic consumption is also significantly reduced in the manufacturing of products realised from blends containing RR2 reclaimed rubber, which is added to that determined by the reduction of the refining time (Table 8, Figure 8).

Table 8. Reducing energy consumption in making products with the use of regenerated rubber RR2, \%.

\begin{tabular}{lcccccc}
\hline & Products & \multicolumn{5}{c}{ Products Made with the Use of Regenerated Rubber RR2 } \\
\cline { 2 - 7 } Reduce Energy Consumption & RR20 & RR21 & RR22 & RR23 & RR24 & RR25 \\
\hline $\begin{array}{l}\text { By reducing refining } \\
\text { time (RRt) }\end{array}$ & 0 & 4 & 8 & 12 & 16 & 20 \\
\hline $\begin{array}{l}\text { By reducing optimum } \\
\text { curing time (ROCt) }\end{array}$ & 0 & 3.4 & 6.9 & 10.5 & 11.2 & 19.7 \\
\hline
\end{tabular}




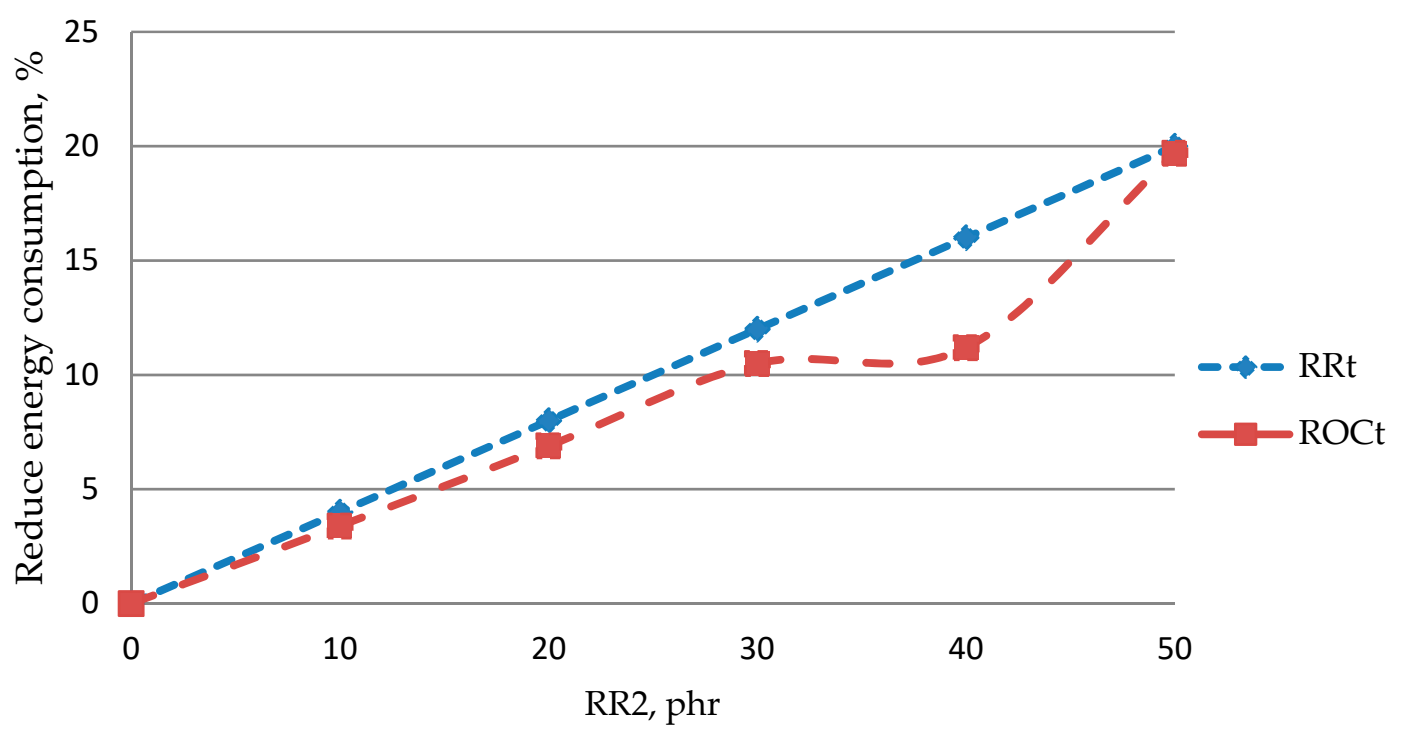

Figure 8. Reducing energy consumption in the case of the use of regenerated rubber RR2.

The analysis of the reduction of energy consumption, as in Table 8 and Figure 8 , has been done when considering the reduction of energy consumption by reducing refining time (RRt) and reducing optimum curing time (ROCt), respectively. From the results that are presented, it can be noticed that the energy consumption can be considerably reduced if RR2 regenerated rubber is used up to $30-40 \mathrm{phr}$. In the interval of 30-40 phr, a stabilization of the energy consumption can be approximately observed. Additionally, for a value that is greater than $40 \mathrm{phr} R \mathrm{R} 2$, analysis is no longer important, because the use of a larger proportion of such regenerated rubber in the products is not indicated.

The reduction in refining time is explained by the fact that the RR2 regenerated rubber moisture is much lower than in the case of RR1 and, thus, the refining process no longer requires the elimination of excess water. In the case of improved technology, there is an additional operation, namely the vacuuming of the autoclave, but the energy consumption of this plant is very small and it is compensated by the fact that no permanent ventilation of the working space is needed, as is the case with regenerated rubber RR1. Thus, if for RR1 reclaimed rubber, the cost of manufacturing is about $0.78 \mathrm{Eur} / \mathrm{kg}$, through the reducing of energy consumption by approximately $1 \mathrm{kWh} / \mathrm{kg}$, the cost of regenerated rubber for RR2 decreases at about $0.65 \mathrm{Eur} / \mathrm{kg}$.

According to the results that are presented in Table 7, it is observed that the percentage of incorporation of the reclaimed rubber in different rubber mixtures, without affecting the physical and mechanical properties, increases from 15-20 phr for RR1 rubber to 35-40 phr for RR2 rubber. When considering that the cost of one $\mathrm{kg}$ of rubber blend without the use of reclaimed rubber is about $1.5 \mathrm{Eur} / \mathrm{kg}$, as opposed to $0.78 \mathrm{Eur} / \mathrm{kg}$ for reclaimed rubber, any increase in the share of reclaimed rubber in a rubber mixture determines a decrease in costs. Thus, the cost of a rubber blend incorporating a maximum of $20 \mathrm{phr}$ RR1 regenerated rubber (maximum value without substantially affecting the physico-mechanical properties) is about $1.36 \mathrm{Eur} / \mathrm{kg}$. The cost of a rubber blend incorporating maximum of $40 \mathrm{phr}$ RR2 reclaimed rubber (maximum value without substantially affecting the physico-mechanical properties) is $1.16 \mathrm{Eur} / \mathrm{kg}$. The analysis of these data shows that the use of the new technology leads to a decrease in the costs of obtaining a rubber mixture of approximately $0.2 \mathrm{Eur} / \mathrm{kg}$, and this highlights the fact that the use of the new type of reclaimed rubber in the rubber mixtures used to make the various products determine a reduction in costs and, consequently, to the energetic consumptions. The costs for products obtained by using the two types of regenerated rubber, RR1 and RR2, are presented in Table 9. 
Table 9. The products cost made using RR1 and RR2 regenerated rubber, Eur $/ \mathrm{kg}$.

\begin{tabular}{|c|c|c|c|c|c|c|c|c|c|c|c|c|}
\hline \multirow[b]{2}{*}{ Cost } & \multicolumn{6}{|c|}{$\begin{array}{l}\text { Products Made with the Use of } \\
\text { Regenerated Rubber RR1 }\end{array}$} & \multicolumn{6}{|c|}{$\begin{array}{l}\text { Products Made with the Use of } \\
\text { Regenerated Rubber RR2 }\end{array}$} \\
\hline & RR10 & RR11 & RR12 & RR13 & RR14 & RR15 & RR20 & RR21 & RR22 & RR23 & RR24 & RR25 \\
\hline Product cost & 1.5 & 1.428 & 1.356 & 1.284 & 1.212 & 1.141 & 1.5 & 1.415 & 1.33 & 1.251 & 1.16 & 1.075 \\
\hline
\end{tabular}

Since RR1 can be used up to a maximum of $20 \mathrm{phr}$ and RR2 of $40 \mathrm{phr}$, the analysis that is made in Table 9 and Figure 9 demonstrates that the cost difference between the products incorporating the two types of regenerated rubber is about $0.2 \mathrm{Eur} / \mathrm{kg}$. This demonstrates the high efficiency of the proposed technology. By improving the devulcanization technology in the sense of applying a vacuum of the autoclave, a series of process improvements have been produced that enable the transformation of the devulcanization process in the autoclave into a sustainable one. Thus, the main sustainability effects are:

- considerably reducing environmental pollution, in the sense that the water vapors in autoclave have not been released into the external environment, but they have been taken up and transformed into water waste that can be subjected to the purification process;

- a low energetic consumptions in the sense that, although an additional autoclave vacuuming operation occurs, it only consumes $10 \%$ of the energy consumption that would have been used in the refining process of the reclaimed rubber;

- by reducing the humidity of the regenerated rubber, better working conditions have been achieved for the workers in the refining process, in the sense that it does not release any toxic substances that are caused by the evaporation of water from regenerated rubber;

- reduction of the moisture content of the regenerated rubber makes the rubber refining process one much more efficient and with considerable energy-saving. Thus, the duration of the refining process is reduced by half when compared to classical technology, and this results in productivity gains and a significant reduction in energetic consumption;

- the possibility of applying rubber devulcanization and to high-wear rubbers, whih, usually, are not subject to the devulcanization process; and,

- the improvement of the physico-mechanical characteristics of the reclaimed rubber enables it to be included in various rubber mixtures that are used in the manufacture of new products with superior technical and economic characteristics.

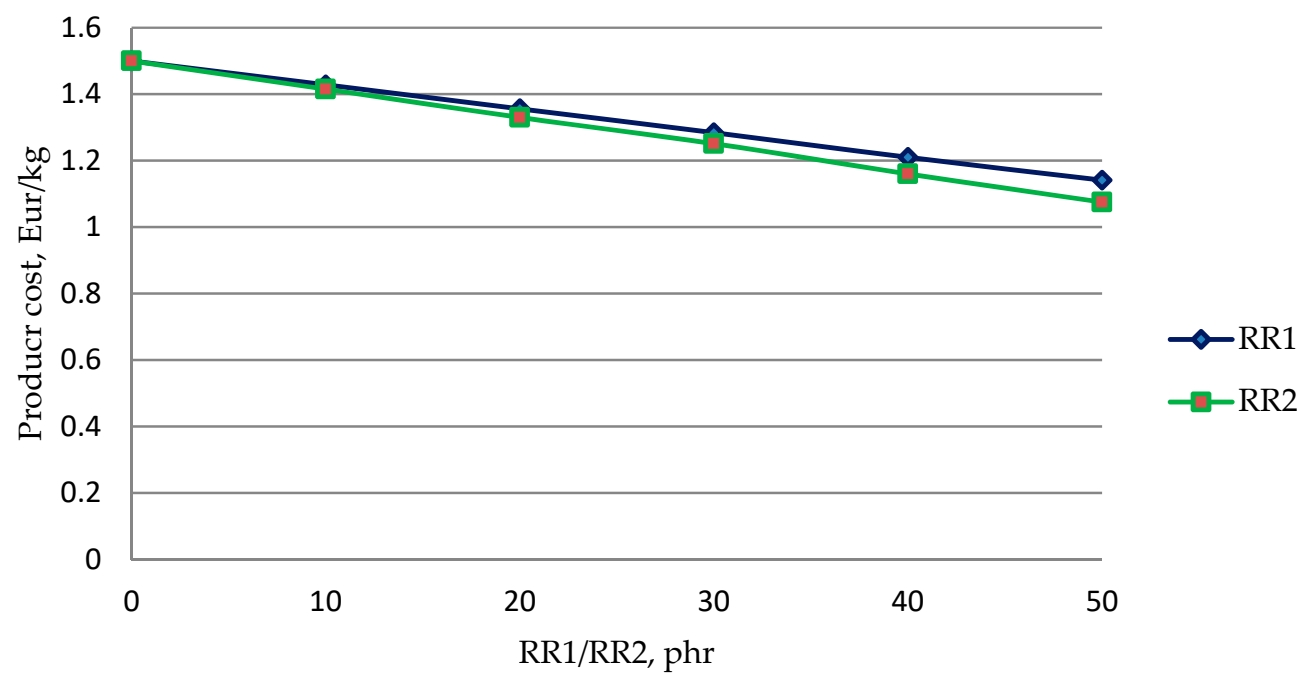

Figure 9. Reducing of products cost made in the case of use RR1 and RR2 regenerated rubber. 


\section{Conclusions}

Finding technological solutions for the superior utilization of rubber waste is a worldwide priority due to the large quantities of waste of this type existing at present. A possible technology that can be applied for the superior utilization of rubber waste is their transformation into reclaimed rubber by devulcanization in autoclaves. In order to obtain a reclaimed rubber with superior characteristics, but also to reduce the environmental pollution that is caused by the devulcanization process, an improvement of the devulcanization in the autoclave technology is required. In this regard, the use of the vacuuming process of the autoclave, after the devulcanization of the rubber, allows for obtaining the following advantages:

- avoiding the pollution of the working environment by removing the water vapors from the autoclave by transforming them into water waste;

- the substantial increase of the degree of devulcanization of the rubber wastes;

- improving the physico-mechanical characteristics of rubber products that have reclaimed rubber in the structure;

- reducing energy consumption in the sense that the devulcanized rubber that was obtained in the vacuum autoclave should not be subjected to a long refining cycle;

- this technology can also be applied to other types of waste containing rubber; and,

- the possibility of using reclaimed rubber in the composition of different types of rubber that are in the structure of different products that require very high technical characteristics.

Author Contributions: D.D. conceptualization and design experiment; G.D. analyzed the data; G.D. writing—original draft preparation; D.D.and G.D. have read, corrected and approved the manuscript.

Funding: This research was funded by Lucian Blaga University of Sibiu, grant number LBUS-IRG-2018-04.

Acknowledgments: Project financed from Lucian Blaga University of Sibiu research grants LBUS-IRG-2018-04.

Conflicts of Interest: The authors declare no conflict of interest.

\section{References}

1. Dobrotă, D.; Dobrotă, G. An innovative method in the regeneration of waste rubber and the sustainable development. J. Clean. Prod. 2018, 172, 3591-3599.

2. Myhre, M.; Saiwari, S.; Dierkes, W.; Noordermeer,J. Rubber recycling: Chemistry, processing, and applications. Rubber Chem. Technol. 2012, 85, 408-449. [CrossRef]

3. Anu, M.J.; Benny, G.; Madhusoodanan, K.N.; Rosamma, A. Cure characteristics of devulcanized rubber: The issue of low scorch. Rubber Chem. Technol. 2017, 90, 536-549.

4. Barge-Gil, A. Open strategies and innovation performance. Ind. Innov. 2013, 20, 585-610. [CrossRef]

5. Rennings, K.; Rammer, C. The impact of regulation-driven environmental innovation on innovation success and firm performance. Ind. Innov. 2011, 18, 255-283. [CrossRef]

6. Dobrotă, D. Experimental research regarding processing rubber waste with metallic insertions. Mater. Plast. 2006, 43, 65-67.

7. Sun, X.; Isayev, A.I. Ultrasound devulcanization: Comparison of synthetic isoprene and natural rubbers. J. Mater. Sci. 2007, 42, 7520-7529.

8. Su, H.; Yang, J.; Ling, T.-C.; Ghataora, G.S.; Dirar, S. Properties of concrete prepared waste tyre rubber particles of uniform and varying sizes. J. Clean. Prod. 2015, 91, 288-296.

9. Movahed, S.O.; Ansarifar, A.; Estagy, S. Review of the reclaiming of rubber waste and recent work on the recycling of ethylene-propylene-diene rubber waste. Rubber Chem. Technol. 2016, 89, 54-78.

10. Dobrotă, D. Adhesion degradation of rubber and steel insert for conveyor belts. J. Adhes. Sci. Technol. 2013, 27, 125-135.

11. Thomas, B.S.; Gupta, R.C.; Panicher, V.J. Recycling of waste tire rubber as aggregate in concrete: Durability-related performance. J. Clean. Prod. 2016, 112 Pt 1, 504-513. 
12. Bernardeta, D.; Lech, L.; Przemysław, M. Assessment of the applicability of sustainable epoxy composites containing waste rubber aggregates in buildings. Buildings 2019, 2, 31. [CrossRef]

13. Zhi, M.; Yang, F.; Meng, F.; Li, M.; Manivannan, A.; Wu, N. Effects of pore structure on performance of an activated-carbon supercapacitor electrode recycled from scrap waste tires. ACS Sustain. Chem. Eng. 2014, 2, 1592-1598.

14. Bleiro, L.; Moreno-Navarro, F.; Tauste-Martínez, R.; Jose Matos, J.; Rubio-Gámez, M.C. Reclaimed polymers as asphalt binder modifiers for more sustainable roads: A Review. Sustainability 2019, 11, 646. [CrossRef]

15. Hassan, M.M.; Aly, R.O.; Abdel Aal, S.E.; El-Masry, A.M.; Fathy, E.S. Mechanochemical devulcanization and gamma irradiation of devulcanized waste rubber/high density polyethylene thermoplastic elastomer. J. Ind. Eng. Chem. 2013, 19, 1722-1729. [CrossRef]

16. Winoto, V.; Yoswathana, N. Optimization of biodiesel production using nanomagnetic CaO-based catalysts with subcritical methanol transesterification of rubber seed oil. Energies 2019, 12, 230. [CrossRef]

17. Zhang, T.; Cao, J.; Wang, X.; Zhang, L.; Zhang, Y. Influences of process variables and dubcritical fluids on EPDM-assisted sevulcanization of SBR-based ground tire rubber. Rubber Chem. Technol. 2018, 91, 401-416.

18. Wu, Q.; Fang, J.; Zheng, M.; Luo, Y.; Wang, X.; Xu, L.; Zhang, C. Morphology evolution and rheological behaviors of PP/SR thermoplastic vulcanizate. Polymers 2019, 11, 175. [CrossRef]

19. Chen, H.; Boqian, L.; Ying, R.; Wu, L.; Yibing, Z.; Weidong, H.; Anchao, F. How the crosslinking agent influences the thermal stability of RTV phenyl silicone rubber. Materials 2019, 12, 88.

20. Ghosh, J.; Ghorai, S.; Bhunia, S.; Madhusudan, R.; Debapriya, D. The role of devulcanizing agent for mechanochemical devulcanization of styrene butadiene rubber vulcanizate. Polym. Eng. Sci. 2018, 58, 74-85.

21. Abbas, M.; Neubauer, M.; Slugovc, C. Converting natural rubber waste into ring-opening metathesis polymers with oligo-1,4-cis-isoprene sidechains. Polym. Chem. 2018, 9, 1763-1766.

22. Colom, X.; Marín-Genescà, M.; Mujal, R.; Formela, K.; Cañavate, J. Structural and physico-mechanical properties of natural rubber/GTR composites devulcanized by microwaves: Influence of GTR source and irradiation time. J. Compos. Mater. 2018, 52, 3099.

23. Zhang, T.; Xing, Z.; Zhang, L.; Zhang, Y. Recycling of resin cured IIR-based ground bladder rubber with the assistance of subcritical fluids. J. Elastomers Plast. 2018, 50, 677.

24. Zedler, L.; Przybysz, M.; Klein, M.; Saeb, M.R.; Formela, K. Processing, physico-mechanical and thermal properties of reclaimed GTR and NBR/reclaimed GTR blends as function of various additives. Polym. Degrad. Stab. 2017, 143, 186-195.

25. Hong, Y.J.; Jeong, K.M.; Saha, P.; Suh, J.; Kim, J.K. Processing and characterization of microwave and ultrasonically treated waste-EPDM/LDPE polymer composites. Polym. Eng. Sci. 2015, 55, 533-540. [CrossRef]

26. Pistor, V.; Zattera, A.J. Degradation kinetics of ethylene propylene diene terpolymer residues devulcanized by microwaves. J. Elastomers Plast. 2014, 46, 69-83. [CrossRef]

27. Mangili, I.; Collina, E.; Anzano, M.; Pitea, D.; Lasagni, M. Characterization and supercritical $\mathrm{CO}_{2}$ devulcanization of cryo-ground tire rubber: Influence of devulcanization process on reclaimed material. Polym. Degrad. Stab. 2014, 102, 15-24. [CrossRef]

28. Holst, O.; Stenberg, B.; Christiansson, M. 1998. Biotechnologicalpossibilities of waste rubber treatment. Biodegradation 1998, 9, 301-310. [PubMed]

29. Forrest, M. Development in Recycling and Re-use of Waste rubber. Available online: http://www.iom3.org/sites/default/files/P9\%20Martin\%20Forrest\%20-\%20Developments\%20in\%

20Recycling\%20and\%20Re-use\%20of\%20Waste\%20Rubber\%20-\%20Final\%20version.pdf （accessed on 15 May 2017).

(C) 2019 by the authors. Licensee MDPI, Basel, Switzerland. This article is an open access article distributed under the terms and conditions of the Creative Commons Attribution (CC BY) license (http://creativecommons.org/licenses/by/4.0/). 